Original Article

\title{
ANALYSIS OF LYNESTRENOL IN HUMAN PLASMA IN VITRO BY HIGH-PERFORMANCE LIQUID CHROMATOGRAPHY UV-VIS: EUROPEAN MEDICINES AGENCY GUIDELINE
}

\author{
NURFITRIYANA NURFITRIYANA¹, HARMITA HARMITA¹, ISKANDARSYAH ISKANDARSYAH'* \\ ${ }^{1}$ Departement of Pharmacy, Physical Pharmacy Laboratory, Faculty of Pharmacy, Universitas Indonesia, Depok, 16424, Indonesia \\ Email: iskandarsyah@farmasi.ui.ac.id
}

Received: 03 Jan 2020, Revised and Accepted: 07 Apr 2020

ABSTRACT

Objective: Development and validation of reverse phase high performance liquid chromatographic (RP-HPLC) method with UV-Vis detector for in vitro determination of lynestrenol with levonorgestrel as an internal standard in human plasma.

Methods: The RP-HPLC method was developed using a $\mathrm{C}^{18}$ Sunfire ${ }^{\odot}$ waters column with a mobile phase of acetonitrile containing $0.1 \%$ formic acid in water (60:40), respectively, at a flow rate of $1.0 \mathrm{ml} / \mathrm{min}$ and was detected at a wavelength of $204 \mathrm{~nm}$. Lynestrenol and levonorgestrel were extracted from human plasma using pentane with protein precipitation method.

Results: The RP-HPLC method was able to selectively quantify lynestrenol in blood plasma on $40 \mathrm{ng} / \mathrm{ml}$. The assay exhibited a linear dynamic range $40-1000 \mathrm{ng} / \mathrm{ml}$ for lynestrenol with retention time 4.0 second, and the coefficient correlation ( $\mathrm{r}$ ) was 0.9994 . Accuracy (\% diff) of this method was$10.81 \%$ to $8.72 \%$ with precision (CV) being $3.84 \%$ to $8.12 \%$, and complete recovery was established to be $98.27 \%$ to $106.49 \%$. The method was sensitive, selective, and has simple sample preparation extraction lynestrenol in plasma with pentane was successfully developed.

Conclusion: The method can be used to analyze lynestrenol in blood plasma, with a simple pretreatment procedure using pentane.

Keywords: HPLC, Lynestrenol, Levonorgestrel, Plasma, In vitro, Validation

(C) 2020 The Authors. Published by Innovare Academic Sciences Pvt Ltd. This is an open access article under the CC BY license (http://creativecommons.org/licenses/by/4.0/] DOI: http://dx.doi.org/10.22159/ijpps.2020v12i5.36763. Journal homepage: https://innovareacademics.in/journals/index.php/ijpps

\section{INTRODUCTION}

Lynestrenol is a derivative of progesterone, which is an endogenous steroid hormone produced by the ovaries, and cortex. Lynestrenol is used for women contraception and as a treatment for menstrual bleeding, maturation of the follicles in the ovaries and ovulation. For menstruation delay, doses of lynestrenol is $1 \mathrm{mg} /$ day, which plasma levels exceeded $0.7 \mathrm{ng} / \mathrm{ml}[1,2]$.

Lynestrenol in the digestive tract is absorbed rapidly with bioavailability, about $64 \%$. Lynestrenol is metabolized in the liver through norethindrone metabolite about $98 \%$. Conversion of lynestrenol to norethindrone through hydroxylation reaction on C-3 and $3 \beta$ hydroxyl-lynestrenol with CYP2CP, CYP2C19, and CYP3A4 enzymes $[3,4]$

Determination of the concentration of drugs in plasma through bioavailability studies that can measure the speed and amount of drugs absorbed by the body is a study of drug products that illustrates the effectiveness of drug preparations [5].

High-performance liquid chromatography (HPLC) methods are commonly used in analyzing drug concentrations in plasma. HPLC can separate substances that interfere with analysis and determine the smallest concentration of drug in plasma $[6,7]$.

Guidelines for validation of bioanalysis methods generally refer to the Food and Drug Administration and also the European Medicines Agency. However, research that refers to EMEA is still rarely done because of relatively new in the revision of the bioanalysis validation method $[8,9]$.

In this research, the liquid-liquid extraction method was performed on human blood plasma obtained from the Indonesian Red Cross. Liquidliquid extraction using pentane and bioanalysis validation of the extraction method used refers to European Medicines Agency guidelines (EMEA). High-Performance Liquid Chromatography used for analysis with a mobile phase of acetonitrile containing $0.1 \%$ format in water $(60: 40)$, a flow rate of $1.0 \mathrm{ml} / \mathrm{min}$ in the reverse phase of column C18 $(150 \mathrm{~mm})$, and detected at wavelength $204 \mathrm{~nm}$ [10].

\section{MATERIALS AND METHODS}

\section{Instrumentation}

High-Performance Liquid Chromatography (Shimadzu, Japan) equipped with a UV-Vis SPD 10A detector. LC-Solution data processor and integrator CBM 102; microsyringe $5 \mu \mathrm{l}$ (Hamilton, Nevada); column C-18 (Waters, SunfireTM $5 \mu \mathrm{m} ; 150$ x $4.6 \mathrm{~mm}$ ); ultracentrifuge (Corning); vortex mixer (VM-300 Germany Industrial Corporation, USA), sonicator (Branson 3200, USA).

\section{Chemical}

Lynestrenol (Indian Penal Code, Pirumadara), Levonorgestrel (Sigma Aldrich, Singapore), Acetonitrile Pro HPLC (Merck), Methanol Pro HPLC (Merck), Formic Acid (Merck), Pentane (Merck), Potassium Dihydrogen Phosphate (Merck), Sodium Hydroxide (Merck), anticoagulant Citrate (Indonesian Red Cross), human blood (Indonesian Red Cross).

\section{Chromatography system}

This study was implementing HPLC with a UV-Vis detector, column C18 with length $150 \times 4.6 \mathrm{~mm}$, detected at $204.0 \mathrm{~nm}$ wavelength, using a mobile phase of acetonitrile containing $0.1 \%$ Formic acid in water (60:40) with a flow velocity of $1.0 \mathrm{ml} / \mathrm{min}$, injection volume was $20 \mu \mathrm{L}$ and used levonorgestrel as the internal standard.

\section{Preparation of standard solution}

$10.0 \mathrm{mg}$ lynestrenol was dissolved in methanol in a $10 \mathrm{ml}$ volumetric flask to obtain $1.0 \mathrm{mg} / \mathrm{ml}(1000 \mathrm{ppm})$ concentration. Levonorgestrel standard $10.0 \mathrm{mg}$ was dissolved in the mobile phase to obtain 1.0 $\mathrm{mg} / \mathrm{ml}(1000 \mathrm{ppm})$. The dilution was conducted to obtain solutions in certain concentrations.

\section{Plasma sample preparations}

The liquid-liquid extraction method was conducted by adding $25 \mu \mathrm{l}$ levonorgestrel $100 \mu \mathrm{g} / \mathrm{ml}$ to $500 \mu \mathrm{l}$ plasma which containing $50 \mu \mathrm{g} / \mathrm{ml}$ lynestrenol and $1 \mathrm{ml}$ buffer phosphate 7.4 in microtube and vortexed for 30 seconds. Next, $1 \mathrm{ml}$ pentane was added, and the mixtures were 
vortexed for $3 \mathrm{~min}$ and then centrifuged at $10.000 \mathrm{rpm}$ for $10 \mathrm{~min}$ on $25^{\circ} \mathrm{C}$. The organic phase was transferred to another tube and repeated three times and evaporated with Nitrogen gas $\left(\mathrm{N}_{2}\right)$, then the residue was reconstituted in $100 \mu \mathrm{l}$ methanol. Afterward, $20.0 \mu \mathrm{l}$ aliquot was injected into the HPLC system.

\section{Validation of lynestrenol analysis in plasma}

Referring to EMEA Guideline for Bioanalytical Method Validation 2011, before validation running, system suitability must be apparent Validation of the lynestrenol analytical method in plasma was conducted with selectivity carry over, LLOQ, linear calibration curve, accuracy, precision, and recovery, dilution integrity, and stability [10].

\section{RESULTS AND DISCUSSION}

The plasma concentration of lynestrenol is relatively low and shows significant inter-individual variations in uptake, storage, and metabolism. The analysis of lynestrenol in human plasma has been reported with detection limits lower than $0.7 \mathrm{ng} / \mathrm{ml}$ by HPLC. Therefore, a more sensitive analytical method is needed to monitor the precise concentrations in plasma during pharmacokinetic studies. The study was performed with low lynestrenol dosing.

A different method for extraction of lynestrenol in plasma is described using C18 solid-phase extraction. Extraction of lynestrenol of this research in plasma with various organic solvents. Extraction with pentane gave high recoveries regardless of the concentration of lynestrenol; therefore, pentane was chosen for the extraction.

Based on the mobile phase was used in this validation is acetonitrile, containing $0.1 \%$ formic acid in water $(60: 40)$. The addition of formic acid on the mobile phase had the desirable effect of maintaining a reasonably high capacity factor (k) resolution (Rs) and tailing factors (Tf) for the analyte. A concentration of $1 \mathrm{mmol}$ formic acid in the mobile phase was large enough to achieve the reproducible elongated retention time $\left(\mathrm{t}_{\mathrm{r}}\right)$ for the analyte [11].

\section{System suitability}

According to the European Medicines Agency in 2011, system suitability tests are an integral part of any liquid chromatographic method. The parameters were performed on lynestrenol and levonorgestrel, including retention time $\left(\mathrm{t}_{\mathrm{r}}\right)$, areas $(\mu \mathrm{V} . \mathrm{s})$, resolutions (Rs), the number of theoretical plates ( $N)$, HETP, and tailing factor (Tf). All these parameters were found to be satisfactory and within the reported acceptance listed in the reference. As shown in table 1 , the tailing factor was $<2$, acceptable retention time along with good resolution is indicative of good efficiency and selectivity of the method for separation of lynestrenol and levonorgestrel as an internal standard.

Table 1: HPLC system suitability parameters for determination of lynestrenol and levonorgestrel

\begin{tabular}{lllllll}
\hline Analytes & Retention time $\left(\mathbf{t}_{\mathbf{r}}\right)$ & Areas $(\boldsymbol{\mu V} . \mathbf{s})$ & resolutions (Rs) & Tailing factors (Tf) & HETP & Theoretical plates (N) \\
\hline Lynestrenol & 4.018 & 11334 & 13.241 & 0.782 & 0.00034 & 21324.5 \\
Levonorgestrel & 5.560 & 8498 & 9.242 & 0.837 & 0.00024 & 2435.4 \\
\hline
\end{tabular}

\section{Lower limit of quantification (LLOQ)}

The LLOQ value is related to the sensitivity of a method, smaller the LLOQ value indicating of more sensitive method that can measure the lowest concentration of analytes from the plasma matrix. In bioanalysis, the LLOQ value must cover a minimum of $1 / 20$ of the maximum concentration ( $\mathrm{C}$ max) of the analyte in the plasma. The LLOQ which meet the requirements giving $\pm 20 \%$ of $\%$ diff (EMEA, 2011). Based on the analysis of lynestrenol in plasma, table 2 shows that the LLOQ value of $40.0 \mathrm{ng} / \mathrm{ml}$ was applied, while that was applied at $20.0 \mathrm{ng} / \mathrm{ml}$ (half concentration), the value of \% diff would rise to above the requirements.

Table 2: LLOQ value of lynestrenol

\begin{tabular}{llll}
\hline Real concentration $(\mathbf{n g} / \mathbf{m l})$ & Measured concentration \pm SD $(\mathbf{n g} / \mathbf{m l})$ & \% CV & \%Diff \\
\hline 40 & $42.596 \pm 2.493$ & 5.853 & -3.445 to 11.786 \\
20 & $14.545 \pm 2.918$ & 20.061 & -34.969 to-1.178 \\
\hline
\end{tabular}

\section{Selectivity}

Selectivity test was conducted in the blank plasma and LLOQ concentrations, $40.0 \mathrm{ng} / \mathrm{ml}$ using six different plasmas (A to F). Each sample was analyzed and evaluated separately to determine interference. The results show, the selectivity study on the blank did not show any interference or impurities during the analysis of the analytes and the internal standard. The results show that the value of the \% interference is $0.063-11.658 \%$. Selectivity data of lynestrenol are shown in table 3.

Table 3: Selectivity value of lynestrenol

\begin{tabular}{lllll}
\hline Real concentration $(\mathbf{n g} / \mathbf{m l})$ & Plasma & Measured concentration \pm SD $(\mathbf{n g} / \mathbf{m l})$ & \% CV & \%Diff \\
\hline \multirow{4}{*}{40} & A & $38.877 \pm 0.217$ & & \\
& B & $42.254 \pm 1.823$ & 6.607 & $0.063-11.658$ \\
& C & $41.365 \pm 2.002$ & & \\
& D & $38.909 \pm 0.836$ & & \\
& E & $39.961 \pm 1.027$ & & \\
\hline
\end{tabular}

\section{Calibration curve and linearity}

The calibration curve consists of plasma blanks (plasma without analytes and internal standards), zero samples (plasma with internal standards) and non-zero plasma (plasma with analytes and internal standards) as many as 7 concentrations, namely $40.0 \mathrm{ng} / \mathrm{ml}, 80.0$ $\mathrm{ng} / \mathrm{ml}, 120.0 \mathrm{ng} / \mathrm{ml}, 250.0 \mathrm{ng} / \mathrm{ml}, 500.0 \mathrm{ng} / \mathrm{ml}, 750.0 \mathrm{ng} / \mathrm{ml}, 1000.0$ $\mathrm{ng} / \mathrm{ml}$. The value of \% diff from the results of the measurement concentration should not deviate more than $\pm 15 \%$, except for LLOQ not to deviate more than $\pm 20 \%$. Based on statistical calculations, a linear regression equation is produced, namely $y=0.023 x+0.252$ with a correlation coefficient $(\mathrm{r})=0.9994$ where $\mathrm{x}$ is the sample concentration, and y is PAR (peak area ratio) between the response area of the analyte with the internal standard as shown in fig. 1 . The calibration curve was linear with the correlation coefficient ( $r>0.9991$ ) in the concentration range from 40.0 to $1000.0 \mathrm{ng} / \mathrm{ml}$. LLOQ concentration of lynestrenol was $60.0 \mathrm{ng} / \mathrm{ml}$, with the CV value of $3.69 \%$ and $\%$ diff between- 3.445 to $11.786 \%$. 


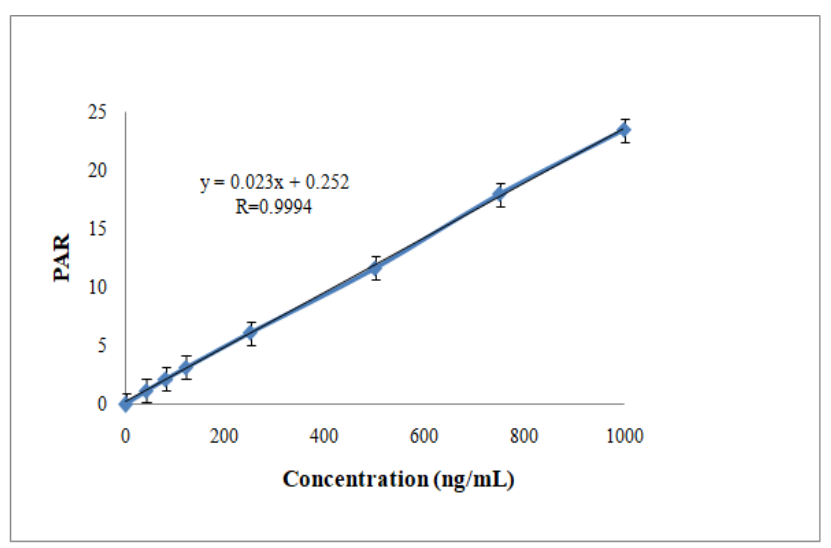

Fig. 1: Calibration curve of lynestrenol

\section{Carry-over}

Carry-over must be minimized during the method development process. During the validation process, carry-over was assessed by injecting blanks, after previously being injected with a high concentration sample or calibration standard on ULOQ (1000.0 $\mathrm{ng} / \mathrm{ml}$ ) of five replicas and analyzed sequentially. Carry-over on the blank should not be more than $20 \%$ of LLOQ and $5 \%$ for internal standards [11]. Carry-over value after injection of high concentrations of lynestrenol range from $2.88 \%$ to $6.09 \%$ of the LLOQ response, while the standard \%carry-over ranged from $0.98 \%$ to $3.35 \%$. Based on research, carry over study results did not exceed the requirements, so it could be concluded during the analysis process that there was no meaningful participation between injections. The chromatogram of blank plasma and chromatogram of ULOQ shown in fig. 2.
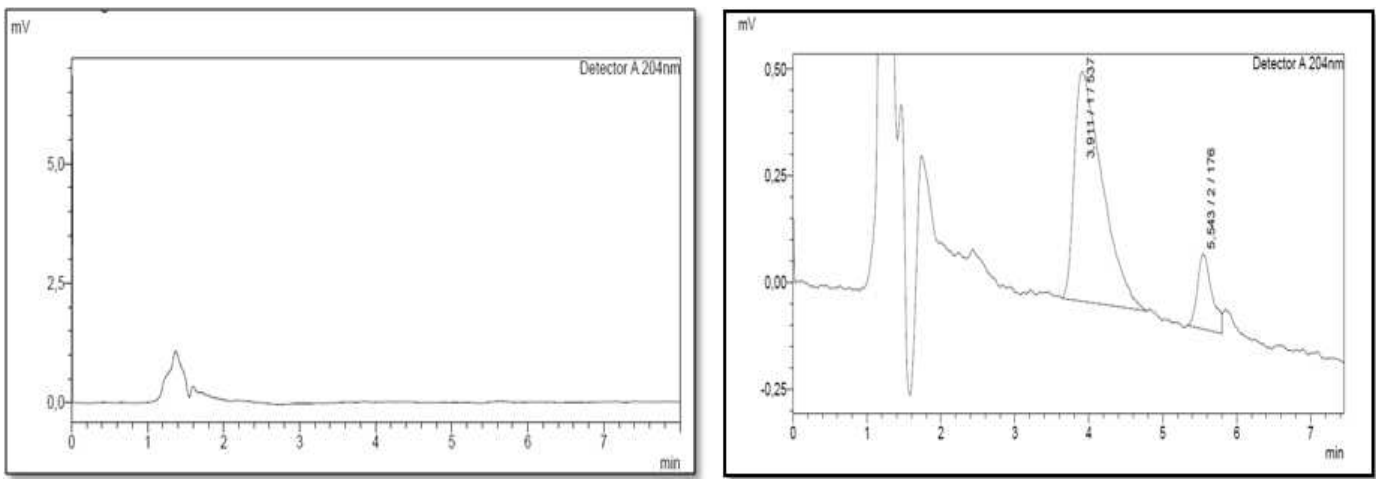

Fig. 2: A representative chromatogram of blank plasma (left) and a representative chromatogram of ULOQ (left), with retention time ( $\left.t_{R}\right)$ of lynestrenol 3.911 and levonorgestrel 5.543 (right)

\section{Accuracy and precision}

In this study, intra-day and inter-day (3 d) accuracy and precision were tested. Lynestrenol in plasma was made at LLOQ concentrations of $40.0 \mathrm{ng} / \mathrm{ml}$, QCL low concentrations of $120.0 \mathrm{ng} / \mathrm{ml}$, QCM moderate concentrations of $500.0 \mathrm{ng} / \mathrm{ml}$, and QCH high concentrations of 750.0 $\mathrm{ng} / \mathrm{ml}$. Based on the results of the study, the accuracy and precision test lynestrenol values obtained\%diff in the four concentrations range from-13.68\% to- $13.81 \%$ and the coefficient of variation in LLOQ concentrations, low, medium and high respectively was $5.62 \%, 7.62 \%$, $8.53 \%$, and $8.25 \%$. The accuracy and precision test results have met the requirements of\%diff, and $\mathrm{CV}$ values do not exceed $\pm 15 \%$ for low, medium, and high concentrations; and at LLOQ concentrations do not exceed $\pm 20 \%$ shown in table 4 .

Table 4: Within run and between run accuracy and precision

\begin{tabular}{|c|c|c|c|c|c|c|}
\hline \multirow{2}{*}{$\begin{array}{l}\text { Actual } \\
\text { cons. } \\
(\mathrm{ng} / \mathrm{ml})\end{array}$} & \multicolumn{3}{|l|}{ Within run } & \multicolumn{3}{|l|}{ Between run } \\
\hline & $\begin{array}{l}\text { Measurable } \\
\text { consentration } \pm S D(\mathrm{ng} / \mathrm{ml})\end{array}$ & $\begin{array}{l}\text { Mean accuracy } \\
\text { (\%diff) }\end{array}$ & $\begin{array}{l}\text { Precision } \\
(\% \mathrm{CV})\end{array}$ & $\begin{array}{l}\text { Measurable concentration } \\
\pm \mathrm{SD}(\mathrm{ng} / \mathrm{ml})\end{array}$ & $\begin{array}{l}\text { Mean accuracy } \\
\text { (\%diff) }\end{array}$ & $\begin{array}{l}\text { Precision } \\
(\% \mathrm{CV})\end{array}$ \\
\hline 40.0 & $40.89 \pm 2.09$ & -4.44 to 6.61 & 4.48 & $40.68 \pm 3.60$ & -3.51 to 8,76 & 8.86 \\
\hline 120.0 & $125.44 \pm 6.68$ & -2.18 to 7.49 & 3.84 & $116.44 \pm 4.74$ & -9.61 to 6.71 & 4.07 \\
\hline 500.0 & $468.31 \pm 24.22$ & -5.42 to 8.72 & 7.17 & $518.57 \pm 30.04$ & -1.28 to 7.90 & 8.53 \\
\hline 750.0 & $726.90 \pm 38.78$ & -10.81 to 1.77 & 8.12 & $785.72 \pm 48.15$ & -4.24 to 9.18 & 6.12 \\
\hline
\end{tabular}

\section{Recovery}

Recovery study was also carried out in the research, with the concentrations used were low, medium, and high concentrations. An absolute recovery study was obtained by comparing the measured concentration with the actual concentration. The results obtained for low, medium, and high concentrations range from 102.41\%-107.94\%, $96.41 \%-106.22 \%$, and $86.32 \%-104.80 \%$, respectively. The coefficient of variation for low, medium, and high concentration analytes were $2.31 \%, 4.71 \%$, and $4.55 \%$, respectively. Next, the extraction efficiency 
study was calculating by \%recovery. The recovery test (\%recovery) provides information about the extraction efficiency of an analytical method under conditions that can change. The results do not have to be $100 \%$ but should be consistent, precise, and reproducible. The $\%$ recovery is obtained by comparing the analyte response that was added after the plasma blank was extracted with the response of the analyte that was extracted. Based on the results of the study, shown in table 3 , the coefficient of variation for low, medium, and high concentration analytes in a row were $2,81 \%, 3.49 \%$, and $8.82 \%$. Recovery data of lynestrenol are shown in table 5.

Table 5: Recovery values of analit and internal standard

\begin{tabular}{llll}
\hline $\begin{array}{l}\text { Actual cons. } \\
\text { (ng/ml) }\end{array}$ & Analit & & Internal standard \\
\cline { 2 - 4 } & \% Recovery $\mathbf{S D D}$ (ng/ml) & CV (\%) & \% Recovery \pm SD (ng/ml) \\
\hline 120.0 & $106.49 \pm 2.95$ & 2.31 & $102.82 \pm 5.73$ \\
500.0 & $99.81 \pm 23.51$ & 4.71 & $98.91 \pm 4.82$ \\
750.0 & $98.27 \pm 33.57$ & 4.55 & $105.82 \pm 6.49$ \\
\hline
\end{tabular}

\section{Dilution integrity}

The effect of dilution was explored to validate that human plasma samples more significant than the highest concentration of the calibration range could be diluted with blank plasma and quantified without losing reproducibility. This parameter serves to assess the dilution process carried out during the bioanalysis process to be accurate, precise, and reliable. The test results obtained must be within the established criteria, namely $\pm 15 \%$. The dilution integrity test must include the dilution used in the study sample [12]. The accuracy and precision values of the dilution still fulfill the strict and precise criteria so that the dilution process carried out during the bioanalysis process can be trusted.

\section{Stability}

The storage stability of lynestrenol was investigated to establish the probability of degradation occurred during long term storage in each plasma. Stability was analyzed using QCL and QCH samples, each with three replications. For the short-term stability, samples were stored at room temperature, and the stability was observed in 0,6 , and $24 \mathrm{~h}$. The obtained results showed that lynestrenol samples were stable to be stored in the room temperature minimum of $24 \mathrm{~h}$, shown in table 6 . The obtained results showed \%diff for the short-term stability of lynestrenol was from-1.95\% to $1.99 \%$, and \%diff for lynestrenol short stability was from-1.85 to-1.64\%. The results showed that the lynestrenol solutions and levonorgestrel solutions were stable when stored at room temperature for a minimum of $24 \mathrm{~h}$.

For long-term stability, samples were stored in the freezer in- $4{ }^{\circ} \mathrm{C}$ for 7 and $14 \mathrm{~d}$. The obtained results showed that lynestrenol samples were stable to be stored in the freezer in $-4{ }^{\circ} \mathrm{C}$ minimum 14 $\mathrm{d}$, shown in table 7 . For long-term stability, the obtained results of $\%$ diff lynestrenol were between- $2.06 \%$ to- $1.96 \%$, and the $\%$ diff of lynestrenol solutions were between- $1.81 \%$ to- $1.57 \%$ for $14 \mathrm{~d}$ in $4{ }^{\circ} \mathrm{C}$. Therefore, lynestrenol and levonorgestrel stock solutions could be used for $14 \mathrm{~d}$.

The freeze-thaw stability test was also conducted. Lynestrenol in plasma was found stable after freeze-thaw test in three cycles minimum. The results are shown in Table 8 . The short-term stability of standard solutions of lynestrenol and the internal standard were tested at room temperature for $24 \mathrm{~h}$. The long-term stability of the standard solutions was stored in $4{ }^{\circ} \mathrm{C}$ for 1,10 , and $18 \mathrm{~d}$.

Table 6: Lynestrenol short-term stability in the plasma in room temperature

\begin{tabular}{llll}
\hline \multirow{2}{*}{ Time } & QCL 120.0 ng/ml & & QCH 750.0 ng/ml \\
\cline { 2 - 4 } & Measurable Concentration \pm SD (ng/ml) & CV (\%) & Measurable concentration \pm SD (ng/ml) \\
\hline 0 hour & $126.26 \pm 6.20$ & 4.91 & $740.72 \pm 38.32$ \\
$6 \mathrm{~h}$ & $128.07 \pm 10.26$ & 8.01 & $740.63 \pm 61.86$ \\
$24 \mathrm{~h}$ & $129.76 \pm 15.96$ & 12.3 & $749.58 \pm 34.63$ \\
\hline
\end{tabular}

Table 7: Lynestrenol long-term stability in the plasma in- $4{ }^{\circ} \mathrm{C}$

\begin{tabular}{llll}
\hline Day & QCL 120.0 ng/ml & & QCH 750.0 ng/ml \\
\cline { 2 - 4 } & Measurable Concentration \pm SD (ng/ml) & CV (\%) & Measurable Concentration \pm SD (ng/ml) \\
\hline 0 & $126.95 \pm 4.82$ & 3.80 & $724.15 \pm 41.70$ \\
8 & $120.46 \pm 4.63$ & 3.84 & $710.63 \pm 36.62$ \\
18 & $123.67 \pm 4.82$ & 3.94 & $729.89 \pm 56.17$ \\
\hline
\end{tabular}

Table 8: Lynestrenol freeze-thaw stability in the plasma

\begin{tabular}{llll}
\hline \multirow{2}{*}{ Cycles } & QCL 120.0 $\mathbf{~ n g} / \mathbf{m l}$ & & QCH 750.0 ng/ml \\
\cline { 2 - 4 } & Measurable consentration \pm SD (ng/ml) & CV (\%) & Measurable consentration \pm SD (ng/ml) \\
\hline 0 & $132.69 \pm 1.68$ & 1.27 & $734.28 \pm 15.88$ \\
3 & $128.07 \pm 2.21$ & 1.72 & $788.47 \pm 30.12$ \\
\hline
\end{tabular}

\section{CONCLUSION}

The method has been validated and can be used to analyze lynestrenol in blood plasma. The simplicity of the assay, with a simple pretreatment procedure using pentane, makes it an attractive procedure for the high-throughput bioanalysis of lynestrenol.

\section{ACKNOWLEDGMENT}

The authors gratefully acknowledge to Directorate of Research and Community Engagements of Universitas Indonesia for financial support: Q1Q2 No. NKB:-0199/UN2. R3.1/HKP.05.00/2019.

\section{AUTHORS CONTRIBUTIONS}

All authors participated in the practical work and writing of the manuscript. Iskandarsyah acted as the corresponding author, and Nurfitriyana acted as the first author, while others as co-authors.

\section{CONFLICT OF INTERESTS}

The authors declared that they have no conflict of interest.

\section{REFERENCES}

1. Hampel M, Wendr H, Dogs G, Weib CHR, Speck U. Intraindividual comparison of pharmacokinetic parameters of 
d-Norgestrel, lynestrenol, and cyproterone acetate in 6 women. Contraception 1977;16:199-215.

2. Kaur S, Kaur T, Kaur G, Verma S. Development and validation of a UV-Spectrophotometric method for estimation of hydroquinone in bulk marketed cream and prepared NLC formulation. Int J Appl Pharm 2017;9:102-8.

3. Korhonen T, Miia T, Ari T, Kari L, Olavi P. Identification of the human cytochrome P450 enzymes involved in the in vitro biotransformation of lynestrenol and norethindrone. J Steroid Biochem Mol Biol 2008;100:56-66.

4. Yasuda J, Hideo H, Hirosi O. Metabolism of lynestrenol: characterization of 3-hydroxylation using rabbit liver microsomes in vitro. J Steroid Biochem 1984;2:777-80.

5. Lalitha KV, Raveendra RJ, Devanna N. Validated stabilityindicating high-performance liquid chromatography method for the estimation of torsemide. Asian J Pharm Clin Res 2019;13:26-32.

6. Shi JYQ, Yao FL, Hu CQ, Yuan QM, Zhang S, Jin H. Establishment of an HPLC identification system for detection of counterfeit steroidal drugs. J Pharm Biomed Anal 2008;46:663-9.
7. Meyer FR. Practical high-performance liquid chromatography. $4^{\text {th }}$ Ed. John Wiley and Sons, New York; 2004.

8. Blister DM. Validating chromatographic methods, a Practical Guide, John Wiley and Sons, Inc., Hoboken; 2006.

9. Harahap Y, Nufus, Firda Z, Sunarsih. Effect of various anticoagulants on ethinyl estradiol and levonorgestrel analysis in human plasma in vitro by ultra-performance liquid chromatography-tandem mass spectrometry. J Global Pharma Tech 2018;10:42-9.

10. European Medicines Agency. Guideline on Bioanalytical Method Validation Vol. 44. London: An agency of the European Union; 2011.

11. Wenkui L, Ying HL, Austin C, Shaolin Z, Weng N. Simultaneous determination of norethindrone and Ethinyl estradiol in human plasma by high-performance liquid chromatography with tandem mass spectrometry-experience on developing a highly selective method using derivatization reagent for enhancing sensitivity. J Chromatography B 2005;825:223-32.

12. Food and Drug Administration. Guidance for Industry: Bioanalytical Method Validation. United States of America: Department of Health and Human Service; 2013. 